\title{
A Twins Study of Communicative Adaptability: Heritability of Individual Differences
}

\author{
Michael J. Beatty \\ Lenora A. Marshall \\ Jill E. Rudd \\ Cleveland State University, J.RUDD@csuohio.edu
}

Follow this and additional works at: https://engagedscholarship.csuohio.edu/clcom_facpub

Part of the Neuroscience and Neurobiology Commons, and the Speech and Rhetorical Studies Commons

How does access to this work benefit you? Let us know!

\section{Publisher's Statement}

This is an Accepted Manuscript of an article published by Taylor \& Francis in The Quarterly Journal of Speech in 2001, available online: https://www.tandfonline.com/doi/abs/10.1080/ 00335630109384346

\section{Recommended Citation}

Beatty, Michael J.; Marshall, Lenora A.; and Rudd, Jill E., "A Twins Study of Communicative Adaptability: Heritability of Individual Differences" (2001). Communication Faculty Publications. 59.

https://engagedscholarship.csuohio.edu/clcom_facpub/59

This Article is brought to you for free and open access by the School of Communication at EngagedScholarship@CSU. It has been accepted for inclusion in Communication Faculty Publications by an authorized administrator of EngagedScholarship@CSU. For more information, please contact library.es@csuohio.edu. 


\title{
A Twins Study of Communicative Adaptability: Heritability of Individual Differences
}

\author{
Michael J. Beatty, Lenora A. Marshall, \& Jill E. Rudd
}

A few years ago, Beatty and McCroskey $(1997,1998)$ proposed a model of communication theory and research within which stable individual differences in communication behavior represent individual differences in activation thresholds of neurological systems thought to underly communication traits. The anatomic features of the neurobiological systems associated with communication apprehension (Beatty, McCroskey, \& Heisel, 1998) and trait verbal aggressiveness (Beatty \& McCroskey, 1997; Valencic, Beatty, Rudd, \& Dobos, 1998) were specified in a series of essays. Informed by the accumulating research literature in the emerging field of psychobiology, Beatty and McCroskey posited the neurobiological systems as mostly, although not exclusively, products of genetic inheritance. As such, Beatty and McCroskey's model assigns a limited role to strategic adaptation in social situations (Beatty \& McCroskey, 2000a, 2000b; Beatty, McCroskey, \& Valencic, 2001). With respect to human adaptability, Beatty and his associates suggested that (1) considerable variance exists among communicators' adaptability and (2) adaptability, itself a trait, is mostly inherited.

The purpose of the present investigation was to provide empirical evidence regarding Beatty and McCroskey's hypothesis about communication adaptability. One widely used approach to estimating heritability relies on the comparison of correlations between variables for identical and fraternal twins (e.g., Hughes \& Cutting, 1999). Although estimating heritability by comparing correlations for identical and fraternal twins has attracted some criticism (e.g., Hoffman, 1991), recent defenses of the design have provided satisfactory responses to the issues. ${ }^{1}$ Hughes and Cutting (1999), for instance, pointed out that the twins design allows researchers "to assess the bottom line of transmissible genetic effects on behavior, regardless of the number of genes involved, the complexity of their interactions, or the influence of nongenetic factors" (p. 429). Furthermore, "The twins design is elegantly simple, and hinges on the fact that monozygotic (MZ) twin pairs are genetically identical, but dizygotic (DZ) twin pairs share an average only $50 \%$ of their genes. Doubling the difference between $\mathrm{MZ}$ and DZ within-pair correlations therefore provides an estimate of the proportion of trait variance attributable to genetic influences (the heritability for that trait)" (p. 429). ${ }^{2}$ These features led Martin, Boomsma, and Machin (1997) to describe the twin design as "the perfect natural experiment" (p. 387). In the present study, estimates of the genetic influence on 
communicative adaptability (Duran, 1983, 1992) were calculated from within-pair correlations for identical (monozygotic) and fraternal (dizygotic) twins.

\section{Conceptual Framework}

\section{Adaptation Construct}

Certainly, the notion that humans differ in their inclination to adapt to situational contingencies during social interaction is a familiar one to communication scholars. Several scholars have presented data in support of the proposition. Snyder (1974) referred to "self monitoring," Hart and his colleagues (Hart \& Burks, 1972; Hart, Carlson, \& Eadie, 1980) studied "rhetorical sensitivity," Delia and Clark (1977) investigated "listener adapted messages" and Duran $(1983,1992)$ developed a construct and measure of "communicative adaptability." Although subtle but important differences exist among the constructs, all share in common the recognition that the degree to which communicators adjust in social settings is unevenly distributed across the population.

In developing their communibiological perspective, Beatty and McCroskey (2000a, $2000 \mathrm{~b}$ ) addressed the apparent paradox of "hard-wired," genetically limiting neurobiological mechanisms on the one hand and human adaptability on the other. They proposed that communicative adaptability, like many other traits, represents manifestations of inherited neurobiological systems. Acknowledging that humans are an adaptive species in the evolutionary sense does not entail the conclusion that most humans are able to strategically adjust their behavior in response to immediate situational demands. The kind of adaptation discussed by evolutionary biologists, sometimes called biological adaptation (e.g., Hettema, 1993), refers to the incremental changes in the characteristics of a species, that occur over generations, in its efforts to survive crises imposed by the environment. As such, the characteristics of a species at any particular point in time are more the product of natural selection than strategic adaptation (Darwin, 1859). Individual members' efforts to cope with challenges posed by immediate circumstances are referred to as social adaptation (Hettema, 1993). Conceptually, communicative adaptability can be viewed as a form of social adaptation. Like social adaptation, communicative adaptability (1) involves strategic dimensions (e.g., use of wit) and emotional reactivity (e.g., social composure) and (2) emphasizes individual differences in the capacity to adapt to immediate surroundings. Based on the distinction between biological and social adaptation, it is not inconsistent to accept the evolution of human capacities to adapt, and, at the same time, question whether humans in general adapt their communication behaviors within the context of daily interactions. ${ }^{3}$

Although the heritability of communicative adaptability has not been studied directly, there is some indirect empirical evidence for Beatty and McCroskey's hypothesis. First, findings from twins research indicate that dimensions of communicator style (Norton, 1978), which are correlated with communicative adaptability, are highly heritable (Horvath, 1995). For example, Horvath (1995) found that the relaxed dimension was $62 \%$ heritable, the open dimension was $78 \%$ heritable, the communicator image dimension was $66 \%$ heritable, and the dominant dimension was $50 \%$ heritable. Second, other traits that could be viewed as components essential to adaptation during social interaction have also been shown to be highly heritable. In their study of identical and fraternal twins, Ruston, Fulker, Neal, Nias, and Eysenck (1986) found that empathy and nurturance, seemingly related to the social confirmation dimension of the CAS (sample items, "while I'm talking, I think about how the other person feels," and "I try to make 
the other person feel important"), were $68 \%$ and $70 \%$ heritable. Horvath (1998) reported that sociability, which seems related to the social experience dimension of the CAS, was $74 \%$ heritable, and that distress and fearfulness, which are similar to the social composure dimension of communicative adaptability, were $94 \%$ and $60 \%$ heritable. Similarly, also using a twins design, Hughes and Cutting (1999) found that "the ability to understand other minds ... (which) enables children to adapt to their social worlds" ( $p$. 429) was approximately $67 \%$ heritable. Overall, many of the psychological and communicative mechanisms underlying adaptability during social interaction appear 10 display considerable genetic influence.

\section{Research Question}

Studies conducted for the purpose of investigating the possible extent of genetic influence on variables do not involve hypothesis testing in the manner traditionally presented in the communication research literature. Rather, researchers pose questions regarding the degree of influence attributable to heredity. Although computing correlations is involved when deriving heritability estimates from twins data, the statistical significance of the coefficients, while often theoretically interesting, is less important than the magnitude of the difference between correlations for identical and fraternal twins. In an effort to empirically examine Beatty and McCroskey's claim, the following research question was posited: To what extent is communicator adaptability heritable?

The significance of the research question resides in part in its implications for the “communibiological paradigm" (Beatty \& McCroskey, 1997, 1998; Beatty, McCroskey, \& Valencic, 2001). If communication adaptability is largely genetic in origin, then Beatty and McCroskey (2000b) have provided at least a partial explanation for the observation of individuals' apparent ability to adjust their behavior: Communicators can adapt but only to the extent they are genetically programmed to do so. However, the less heritable communication adaptation appears to be, the weaker Beatty and McCroskey's argument. Although no single study can provide definitive proof for any claim, the present study poses an important empirical test of Beatty and McCroskey's proposition.

\section{Method}

\section{Participants}

Sampling procedure. Initially, 390 twins attending the "Twins' Day" festival, an annual event held in Twinsburg, Ohio, were contacted and invited to participate in the present study. Ultimately, complete sets of data were available for 210 participants $(105$ twin pairs), representing 30 U.S. states. Of these respondents $(M$ age $=41.76$, Male $=56$, Female = 154), 62 pairs were identical and 43 pairs were fraternal twins, which constitutes a slightly more balanced sample ratio of $\mathrm{MZ}$ to DZ twins than is typical of twins studies (Lykken, 1982).

Confirmation of zygosity. In an effort to confirm participants' self-reports of whether they were identical (monozygotic) or fraternal (dizygotic) twins, analysis of physical differences, twin confusion, and overall impressions from questionnaire responses were conducted. In previous research, examining twins' responses to questions from this combination of factors has yielded high degrees of agreement (95-97\%) with diagnoses of zygosity achieved through blood typing (e.g.. Spitz et al., 1996). The diagnosis of 
zygosity based on the physical appearances and twin confusion data alone produced unambiguous classification of participants' zygosity for 100 of the 105 pairs, with the zygosity of the remaining five pairs determined through the analysis of overall response patterns using the procedures described by Claridge, Center, and Hume (1973). The overall impression was based on the impressions of two raters who achieved high agreement $(100 \%)$ regarding their independent classification of whether the pair was identical or fraternal.

\section{Communicative Adaptability}

Duran and Kelly's (1988) 30-item version of the Communicative Adaptability Scale (CAS) was used to measure adaptability in the present study. Although in previous research, the CAS has been shown to be multidimensional, the number and content of the factors seems to depend on the sample (Duran, 1992). Following the general recommendation that the factor structure of the CAS should be established for a particular sample, especially for samples of noncollege populations (Duran, 1992), we submitted the CAS to factor analysis in the present study.

In light of the objective of determining heritability, it was essential to produce uncorrelated variables. Otherwise, it is impossible to separate direct and indirect (due to collinearity from other variables) genetic influences. Although CAS factor structures were derived through oblique rotation in the development studies (Duran, 1983; Duran \& Kelly, 1988), orthogonal rotation was performed in the present study because estimates of the unique influence of genetics on a set of variables are blurred when those variables are intercorrelated. Orthogonal rotation reduces the data to a set of relatively uncorrelated factors, leading to a cleaner factor by factor analysis of heritability. Because interfactor correlations in previous research (See, Duran, 1992) have been as high as .53 for some factors (e.g., "social experience" and "social confirmation"). Therefore, the unrotated matrix was examined prior to executing rotational procedures to protect against producing a "forced" factor structure.

Analysis of the unrotated factor matrix indicated that only 22 of the 30 items posted their absolute highest factor loading on a factor other than the first factor. In addition, the pattern of loading for the unrotated matrix indicated clusters of items rather than random disbursement across factors. Following McCroskey and Young's (1979) guidelines, a unidimensional interpretation of the matrix was rejected, and orthogonal rotation was performed. Criteria for interpreting the rotated factor solution were: (a) a primary loading of a least .60 and no secondary loading greater than .40 was required to consider an item loaded on a factor and, (b) at least two items meeting the loading criteria and an eigenvalue of at least 1.00 was required to define a set of items as a factor.

The principal components factor analysis, followed by varimax rotation and interpreted in light of the preceding criteria, produced a five-factor model accounting for $63.9 \%$ of the total variance. Factor 1, labeled "Social Composure" consisted of six items and accounted for $16.94 \%$ of the variance (primary factor loadings ranged from .80 to .65 ; secondary loadings ranged from .00 to .22 ; Eigenvalue $=3.90$ ). Specifically, the items were: "My voice sounds nervous when I talk with others," "I feel nervous in social situations," "I enjoy meeting new people," "In most social situations I feel tense and constrained," "I like to be active in different social groups," and "I am relaxed when talking to others." The alpha reliability coefficient was .87 for this factor $(M=21.46$, $s d=4.28$ ). 
Factor 2, labeled "Wit," consisted of five items (primary factor loadings ranged from .86 to .68 ; secondary loadings ranged from .19 to .05 ; Eigenvalue $=2.97$ ). These items were: "When I am anxious, I often make jokes," "When I embarrass myself I often make a joke about it," "I often make jokes when in tense situations," "When someone makes a negative comment about me, I respond with a witty comeback," and "People think I am witty" $(M=14.48, s d=4.09$; alpha reliability coefficient $=.83)$.

The third factor, labeled "Articulation," accounted for an additional $12.64 \%$ of the variance (Eigenvalue $=2.91$ ). The five items forming this factor were: "I have difficulty pronouncing some words," "I sometimes use one word when I mean another," "I sometimes use words incorrectly," "At times I don't use appropriate verb tense" and "When speaking I have problems with grammar." The primary loadings for items on this factor ranged from .81 to .71 , secondary loadings ranged from .00 to .19 , and the alpha reliability coefficient was $.81(M=18.72, s d=3.20)$.

"Social confirmation," the fourth factor, consisted of four items and accounted for an additional $10.87 \%$ of the variance (Eigenvalue $=2.50$ ). The items were: "I try to make the other person feel important," "While I'm talking I think about how the other person feels," "I try to be warm when communicating with another," and "I try to make the other person feel good," $(M=15.90, s d=2.32$, alpha reliability coefficient $=.78)$. The primary factor loadings ranged from .79 to .70 and the secondary loadings ranged from .06 to .24 .

The fifth factor, labeled "Appropriate Disclosure," consisted of three items, accounting for an additional $10.54 \%$ of the variance (Eigenvalue $=2.43$ ). These items were: "When I self-disclose, I know what I am revealing," "I know how appropriate my self-disclosures are" and "I am aware of how intimate my disclosures are." The primary loadings ranged from .85 to .78 and the secondary loadings ranged from .01 to .19 $(M=11.77, s d 2.08$, alpha reliability coefficient $=.84)$.

\section{Procedures}

In general, the procedures used by Horvath (1995) were followed in the present study. Accordingly, participants were approached by one of two female researchers, and then recruited for participation in the present study. The researchers informed the potential participants that the study was university affiliated and approved by the human subjects committee. Names, addresses, and phone numbers were recorded for those who volunteered. Two weeks following the festival, participants were contacted by phone and told to expect a packet of materials pertaining to the research project. A packet containing a cover letter reaffirming the university affiliation, an informed consent form, the questionnaire presenting the CAS items, the zygosity questions and demographic inquires, and a stamped, addressed envelope for returning the materials, was mailed to each potential participant. Anonymity was ensured, using numbered questionnaires for the purpose of matching twins' responses.

In an effort to increase response rate, each participant was contacted by phone to emphasize the importance of their contribution to the research, and to remind participants not to collaborate with their twins when responding to questionnaire items. The response rate was $65.6 \%$ in the present study. Furthermore, all of the participants reported having responded to the items independent of communication with their twins. 


\section{Results}

Pearson product-moment correlation coefficients were calculated for both identical (MZ) and fraternal (DZ) twins for each of the five CAS dimensions. Although both disattenuated and attenuated correlation coefficients are reported in Table 1, heritability estimates were based on disattenuated coefficients, eliminating the differential effects of measurement error on estimates. As reported in Table 1, the genetic influence on communicative adaptability varied greatly across the dimensions. Applying the commonly accepted formula (e.g., Falconer, 1989), in which the difference in MZ and DZ correlations is doubled, resulted in the following estimated proportion of variance in each CAS dimension attributable to genetic sources: Social Composure $=.88$, Wit $=$ .90 , Articulation $=.00$, Social Confirmation $=.36$, and Appropriate Disclosure $=.00$.

\section{Discussion}

The purpose of the present study was to derive estimates of the heritability of communicative adaptability from data collected through the use of a twins design. Heritability estimates spanned a wide range across the dimensions of communicative adaptability. The results of the present study have important implications for communication theory and research in general and for the communibiological perspective in particular.

\section{Implications for Communibiological Theory and Research}

With respect to the theoretical yields of the present study, the implications are two-fold. First, the results for social composure and wit, indicating that both dimensions are highly heritable, corraborate Beatty, McCroskey, and Heisel's (1998) projection regarding the heritability of communication apprehension and related constructs. When the item content for social composure and the attenuated correlation coefficient of .68 between a version of the social composure factor and a measure of communication apprehension (CA) reported in previous research (Duran, 1983) are considered, the finding that social composure was $\mathbf{8 8 \%}$ heritable supports Beatty et al.'s assertion that the heritability of CA may be a high as $80 \%$.

TABLE 1

ATtenuated and CORRECTEd CORRELATION COEFFicients FOR MZ AND DZ PaIRS and Heritability Estimates $\left(\boldsymbol{H}^{2}\right)$ FOR Each CAS Dimension

\begin{tabular}{|c|c|c|c|}
\hline & \multicolumn{2}{|c|}{ Correlations } & \multirow[b]{2}{*}{$h^{2}$} \\
\hline & MZ Pairs & DZ Pairs & \\
\hline \multicolumn{4}{|l|}{ Dimension } \\
\hline Social Composure & $.69(.76)$ & $.28(.32)$ & .88 \\
\hline Wit & $.60(.72)$ & $.22(.27)$ & .90 \\
\hline Articulation & $.36(.44)$ & $.37(.46)$ & .00 \\
\hline Social Confirmation & $.20(.26)$ & $.06(.08)$ & .36 \\
\hline Appropriate Disclosure & $.34(.40)$ & $.40(.48)$ & .00 \\
\hline
\end{tabular}

Note. Coefficients in parentheses are corrected for attenuation. Heritability estimates are zero for any trait in which the $\mathrm{DZ}$ correlation coefficient is equal to or larger than to MZ coefficient. Degrees of freedom are 62 and 43 for the $M Z$ and $D Z$ pairs, respectively. 
The wording of the item pool for the social composure factor is important. Except for one item, the social composure items reference "nervousness," "relaxation," or "ten sion" in social situations. Although we retained the "social composure" label that Duran originally assigned to the factor, we could have alternatively referred to the item set as "social nervousness" or "social anxiety." Reinforcing the extrapolation to CA, correcting the correlation coefficient for attenuation reported by Duran (1983) produces a correlation coefficient of approximately .80 between social confirmation and CA, indicating a high degree of empirical overlap between the two measures. Given that the correlation coefficient not its square indicates the percentage of shared variance for concurrent validity coefficients (Ozer, 1985), it is unlikely that the heritability estimate would have been substantially less for CA than for social composure, especially in light of the item content.

In a similar way, the strong influence of genetic inheritance on wit is informative about Beatty and his associates' perspective. It is noteworthy that all but one of the items that loaded on this factor assess the inclination to employ wit in response to anxiety, embarrassment, or conflict. The contextualization of wit within the item set might be viewed as confounding a witty disposition with the tendency to employ wit as a coping strategy during episodes of social discomfort. However, because the purpose of the CAS was to measure adaptability rather than a tendency to be humorous in general, the social context information was essential. While the findings for social composure suggest that the predisposition to experience emotional distress during social interaction is largely inherited, the findings for wit indicate that at least one coping behavior in response to social distress is also heavily influenced by genetic endowment. If we understand wit as a verbal manifestation of intelligence, the theoretical significance of the rather large heritability coefficient for wit (.90) can be appreciated. General intelligence is among the most heritable traits studied in the personality literature (Lykken, 1995; Segal, 1999). Studies of identical twins raised apart, for example, have consistently produced correlation coefficients in the .75 range for IQ (Lykken, 1995). It should not be surprising, therefore, that wit is also highly heritable.

Second, the findings for the remaining three dimensions of adaptability, (social confirmation, articulation, and appropriate disclosure) complicate theoretical matters but raise interesting questions for future research. Social confirmation was $36 \%$ heritable on the basis of the present data. Although in most studies, accounting for $36 \%$ of the variance would be interpreted as a strong effect, the influence of genetics on social confirmation was somewhat less than for social composure and wit. Moreover, the estimate for social confirmation is far less than would be expected based on Beatty and McCroskey's (1998) assessment of the impact of heredity on traits in general.

Articulation and appropriate self-disclosure appear to have no genetic contribution to their development. The magnitude of the correlations for both sets of twins on these dimensions, given no apparent genetic influence, indicates some effect of shared environment. What accounts for the huge differences in heritability estimates among factors of the same instrument, given that all correlations were corrected for attenuation? One difference between social composure, wit, and to a lesser extent social confirmation, and the other two factors might involve an affect-performance distinction. Social composure focuses on how respondents feel during social interaction and wit deals with attempts at humor during uncomfortable encounters. Articulation and appropriate self-disclosure include effectiveness or correctness as criteria for agreement with an item. Social confirmation seems to consist of a mix of affect and performance. It may be that 
affect and coping strategies during discomfort are largely genetic in origin whereas language-related skills are not. This interpretation is consistent with the notion, for example, that humans are neurobiologically programmed to engage in language but the specific language and the rules for engagement are social products (e.g., Chomsky, 1986).

Before assigning theoretical meaning to findings that indicate no effect, however, methodological explanations must be explored. One methodological complication regarding the differential heredity estimates among the factors concerns the knowledge needed to accurately respond to scale items. For instance, the scale items for social confirmation and wit require only self-knowledge regarding how the respondent feels during social interaction and, perhaps in the case of wit, what the respondent attempts to do. There are no inquiries within the wit items that require an assessment of whether witty comments were perceived by others as effective. In contrast, respondents can only report self-perception of how articulate they are in social situations and whether their self-disclosures are appropriate. Accurately self-assessing those functions probably requires feedback from others regarding competence and appropriateness. Thus, if twins circulate in different social groups and receive different feedback regarding their performance, they would be expected to respond differently to self-report scales even though their actual behaviors might be nearly identical. If the items measuring wit, for example, focussed on the effectiveness of respondents' attempts, the heritability estimate might have been much less than .90 . Items tapping emotional reactions, such as those related to social composure require only self-perceptions. Although it may well be that articulation and wit are not influenced by genetic inheritance, observational studies of twins' comparative level of articulation and appropriateness of disclosure are probably needed before such conclusions are reached.

Methodological reservations aside, the diversity of heritability estimates across the five dimensions of communicative adaptability suggests that Beatty and McCroskey (1998) were fundamentally correct about the magnitude of genetic influence on some traits (e.g., anxiety-related traits) but profoundly incorrect about the breadth of communicator traits that are primarily inherited. The results of the present study are inconsistent with skepticism regarding the claim that communication apprehension may be $80 \%$ genetic (Beatty, McCroskey, \& Heisel, 1998), for example. However, the findings for articulation and appropriate disclosure support reservations about the scope of the communibiological perspective. If the pattern of results reported in the present study are replicated across similar constructs, it may be that Beatty and McCroskey's speculation about the role of genetics provides a strong conceptual foundation for understanding affect components of communication, which makes sense given its neurobiological roots in emotional systems, but fails to provide a comprehensive model of other communication processes. Ultimately, however, the overall value of the communibiological perspective probably resides in the role prescribed to emotion and affect in communication.

The implications of these findings for future research are two-fold. First, the results of the present study indicate that social composure and wit are largely inherited and that social confirmation is moderately so. Similar to Horvath's (1995) study, some of the dimensions of important communicator traits appear to be strongly influenced by genetics. Although Beatty and McCroskey have posited a broad-based perspective, the present study and Horvath's work mark the only two studies of genetic influence in the communication literature. In light of the numerous traits and individual differences that 
have been advanced, further investigation into the heritability of those traits seems warranted. After all, glimpsing the degree to which stable inclinations among commu nicators are bound by genetic influence is relevatory about the etiology of a trait and its nature.

Second, the neurobiological processes underlying the genetically inherited features of communicative adaptability need mapping and verification. Given the connection between social composure and communication apprehension, the constructs are likely to share many of the neurological components described by Beatty, McCroskey, and Heisel (1998). Some of the neurobiological circuitry involved in social confirmation has been identified (e.g., Beatty \& McCroskey, 1997) but to a lesser degree. The neurobiology of wit and much of the other constructs is not well understood. Considering that the behavior and affect of the inherited dimensions are manifestations of underlying neurobiology, theory can be greatly elaborated when the physiological mechanisms are understood more precisely.

\section{General Implications}

The results of this study focus attention on the discipline of communication within the broader "nature/nurture" question. A decade ago, Cappella (1991) advised communication scholars to examine biological explanations rather than rigidly adhering to social learning models. Since that time, a considerable body of evidence, and not just from twin studies, has accumulated that indicates nature plays a far more important role in the development of human interaction practices than previously imagined (for a review, see Beatty, McCroskey, \& Valencic, 2001). We certainly acknowledge that some scholars balk at framing the nature/nurture issue as an either/or proposition. However, the fact remains that the greater the influence of nature, the smaller the effect of nurture. Instead of arguing about whether one perspective is simplistic or offensive to a particular view of what it means to be human, explanations should be accepted or rejected on the basis of the research evidence. Delving into the biological domain, however, challenges communication scholars to sharpen research skills in all regards.

One outcome that communication scholars must expect is that many of the heritability estimates for communication constructs will be considerably larger than routinely found by psychobiologists or sociobiologists. We should expect this because genetic effects are greatest when environmental conditions are held constant (Segal, 1999). Many of the dimensions of social behavior such as "fearfulness," "psychoticism," and "happiness" studied in psychology are broad constructs, cutting across situations. However, communication phenomena are conceptualized and measured in ways that build in a limiting context (i.e., communication). Indeed, it is precisely the contextual boundaries specified by the scholar that defines a particular construct as "communication" and provides theoretical separation from other disciplines. The fact that commu nication represents a subset of human behavior by its very nature suggests limitation of environmental variance. Therefore, large heritability estimates such as those reported in this study for social composure and wit should not be surprising.

Students of communication are interested not only in typologies of rhetorical strate gies but they inquire about why people select specific tactics and why those tactics have different effects on different audiences. Our students are also interested in why some communicators seem unable to switch tactics even in the face of gross ineffectiveness (e.g., Al Gore). Investigations of possible biological origins of message production, 
including elements of planning and execution, and message effects complement descriptive studies. Uncovering genetic influences facilitates completion of the "big picture" of what it means to be rhetorical beings. Indeed, Kenneth Burke (1950) for one underscored the value of understanding the nature of the speaker and listener when he included the "actor" in the pentad. It is becoming increasingly clear that attention to individual differences in neurobiological functioning is necessary to fully appreciate the forces underlying significant communicative acts and effects whether in interpersonal, relational, group, organizational, mediated, or rhetorical contexts.

\section{Notes}

MichaelJ. Beatty (Ph.D., Ohio State University, 1976) is Professor of Communication, University of Missouri-St. Louis, St. Louis, MO 63121. Lenora Marshall received a M.A. in Communication (1998) at Cleveland State University. Jill E. Rudd (Ph.D., Kent State University, 1992) is Associate Professor of Communication, Cleveland State University. This study was based on data collected by the second author as partial completion of the M.A. thesis under the direction of the frrt author.

'One of the inithal criticisms of the twins design concerns the potential confounding effect of common environment on correlations derived from identical twins. The thrust of the argument is that it is difficult to determine whether observed similarities between identical twins are due to common genetics or similar upbringing. However, this objection is flawed in at least four crucial ways. First, researchers have long known that the correlations for twins raised together and twins raised apart are remarkably similar (e.g., Bouchard, Lykken, McGue, Segal, \& Telligen, 1990; Loehlin \& Nichols, 1976; Lykken, 1995; Shields, 1962). Second, research indicates that even when identical twins are treated alike, they do not demonstrate greater behavioral or personality resemblance than identical twins who are treated less alike (e.g., Loehlin \& Nichols, 1976). Third, biologically unrelated infants of the same age who are adopted into families and raised as twins (sometimes referred to as pseudotwins) show far less subsequent resemblance in personality than do nonidentical twins raised together (Segal, 1999). Importantly, fraternal twins share approximately $50 \%$ of their genes in common whereas pseudotwins share none in common. Finally, estimates of heritability are not based solely on the correlations for identical twins. All formulas for heritability remove potential environmental effects by subtracting correlations for fraternal twins, which contain possible effects of shared environment, from identical twin correlations. Overall, then, this criticism of the twins design is not consistent with the extant research literature.

'Some scholars have erroneously claimed that multiplying the difference between identical twins' and fraternal twins' correlations "inflates" heritability estimates (e.g., Condit, 2000). However, an elementary understanding of the genetic composition of each group illuminates the necessity of the adjustment. Recall that the objective of the formula is to remove the variance due to shared environment from that due to common genetics. If fraternal (nonidentical) twins were like pseudotwins, sharing no genes in common (see footnote 1), then merely subtracting the correlations would be sufficient. Unlike pseudotwins, however, fraternal twins share $50 \%$ of their genes. Therefore, the correlations for fraternal twins are not simply estimates of shared environment. When deriving heritability estimates from correlations obtained from identical and fraternal twins, the most commonly accepted formula devised by Falconer (1989) is:

$$
\begin{aligned}
h^{2} & =2\left(\mathbf{R}_{\mathrm{MZT}}-\mathbf{R}_{\mathrm{DZT}}\right) \\
& =2\left[\left(\mathrm{~V}_{\mathrm{g}}+\mathrm{V}_{\mathrm{se}}\right)-\left(1 / 2 \mathrm{~V}_{\mathrm{g}}+\mathrm{V}_{\mathrm{se}}\right)\right] \\
& =2\left(1 / 2 \mathrm{~V}_{\mathrm{g}}\right) \\
& =\mathrm{V}_{\mathrm{g}}^{\prime}
\end{aligned}
$$

In the above, $h^{2}$ represents the estimated heritability, $\mathrm{R}_{M Z T}$ and $\mathrm{R}_{\mathrm{DZT}}$ symbolize the correlations of identical and fraternal twins, $V_{\text {se }}$ stands for the proportion of variance attributable to shared environment, $V_{g}$ is the genetic variance, and $\mathrm{V}_{\mathrm{g}}^{\prime}$ represents the estimate of $\mathrm{V}_{\mathrm{g}}^{\prime}$. If heredity estimates were derived by comparing correlations of half-siblings (who share about $25 \%$ of their genes), cousins (who share about $12.5 \%$ of their genes) or pseudotwins (who share no common genes) identical twins' correlations, the constant would be proportinnately less than 2 . Clearly, the ideal "control" group for heritability studies would consist of pseudotwins because correlations between variables would represent only environmental consequences. Unfortunately, however, few pseudotwin pairs exist, and they are difficult to locate.

${ }^{3}$ Duran's (1992) empirical work is informative about Beatty and McCroskey's position regarding the level of adaptability. Specifically, when descriptive data that Duran (1992) drew from four separate samples (total $N=461$ ) are examined, the notion that humans, as a species, are not highly adaptive does not seem unreasonable. The Communication Adaptability Scale (CAS) consists of 30 items, featuring a five-point response format $(1=$ Never 
True of Me; $2=$ Rarely True of Me; $3=$ Sometimes True of Me; $4=$ Often True of Me; $5=$ Always True of Me:. Given these semantic anchors, individuals who consistently selected "sometimes true of me" would post CAS total scores of 120 . However, Duran (1992) reported a mean for the CAS of 89.01 , slightly less than the hypothetical neutral point, corresponding to an average response of "sometimes true of me." In light of the reported standard deviation $(s . d .=10.14)$, scores of 120 are nearly three standard deviations above the mean. According to the respondents' self-reports, those for whom adaptation is "often true" are statistically rare. Scores indicaling an inclination somewhere between "often" and "always" adapting are even more rare, over four standard deviations above the mean. Although some individuals are clearly highly adaptable, the data just discussed seen to suggest that communicators who often attempt to adapt to social demands are not common.

\section{Works Cited}

Beatty, M.]., \& McCroskey, J.C. (1997). Il's in our nature: Verbal aggressiveness as temperamental expression Communication Quarterly, 45, 446-460.

Beatty, M.J., \& McCroskey, J.C. (1998). Interpersonal communication as temperamental expression: A communibiological paradigm. In J.C. McCroskey, J.A. Daly, M.M. Martin, \& M.J. Beatty (Eds.), Communication and personality Trait perspectives (pp. 41-68). Cresskill, N]: Hampton.

Beatty, MJ., \& McCroskey, J.C. (2000). A few comments about communibiology and the nature/nurture question. Communication Education, 49, 25-28. (a)

Beatty, M.J., \& McCroskey, J.C. (2000). Theory, scientific evidence, and the communibiological paradigm: Reflections on misguided criticism. Communication Education, 49, 36-44. (b).

Beatty, M.J., McCroskey, J.C., \& Heisel, A.D. (1998). Communication apprehension as temperamental expression: A communibiological paradigm. Communication Monographs, 65, 197-219.

Beatty, M.J., McCroskey, J.C., \& Valencic, K.M. (2001). The biology of communication: A Communibiological perspective. Cresskill, NJ: Hampton

Bouchard, T.J., Jr., Lykken, D.T., McGue, M., Segal, N.L., \& Telligen, A. (1990). Sources of human psychological differences: The Minnesota Study of Twins Reared Apart. Science, 250, 223-228.

Burke, K. (1950). A rhetoric of motives. New York: Prentice-Hall.

Cappella, J. (1991). The biological origins of automated patterns of human interaction. Communication Theory, 1, 4-35.

Chomsky, N. (1986). Knowledge of language: Its nature, origin, and use. New York: Praeger.

Claridge, G., Center, S., \& Hume, W.I. (1973). Personality differences and biological variations: A study of twins. New York: Pergamon Press.

Condit, C.M. (2000). Culture and biology in human communication: Toward a multi-causal model. Communication Education, 49, 7-24.

Darwin, C. (1859). The origin of species by natural selection or the presenation of favoured races in the struggle of life. London: Murray.

Delia, J.G., \& Clark, R.A. (1977). Cognitive complexity, social perception, and the development of listener-adapted communication in six-, eight-, ten-, and twelve-year-old boys. Communication Monographs, 44, 326-345.

Duran, R.L. (1983). Communication adaptability: A measure of social communicative competence. Communicalion Quarterly, 31, 320-326.

Duran, R.L. (1992). Communicative adaptability: A review of conceptualization and measurement. Communication Quarterly, 40,253-268.

Duran, R.L., \& Kelly, L. (1988). An investigation into the cognitive domain of competence II: The relationship between communicative competence and interaction involvement. Communication Research Reports, 5, 91-96.

Falconer, D.S. (1989). Introduction to quantitative genetics. New York: Wiley.

Hart, R.P., \& Burks, D.M. (1972). Rhetorical sensitivity and social interaction. Speech Monographs, 39, 75-91

Hart, R.P., Carlson, R.E., \& Eadie, W.F. (1980). Attitudes toward communication and the assessment of rheiorical sensitivity. Communication Monographs, 47, 1-22.

Hettema, J. (1993). Biosocial adaptation: A strategic-tactical approach to individuality. In J. Hetterna \& I.J. Deary (Eds.) Foundations of personality (pp. 139-164). Netherlands: Kluwer Academic Publishers.

Hoffman, L.W. (1991). The influences of the family environment on personality: Accounting for sibling differences. Psychological Bulletin, 110, 189-203.

Horvath, C.W. (1995). Biological origins of communicator style. Communication Quarterly, 43, 394-407

Hughes, C., \& Cutting, A.L. (1999). Nature, nurture, and individual differences in early understanding of mind. Psychological Science, 10,429-432.

Loehlin, J., \& Nichols, R. (1976). Heredity, environment, and personality: A study of 850 sets of twins. Austin, TX: University of Texas Press.

Lykken, D.T. (1982). Research with twins: The concept of emergenesis. Psychophysiology, 19, 361-373 
Lykken, D.T. (1995). The antisocial personalities. Hillsdale, NJ: Lawrence Erlbaum.

Martin, N., Boomsma, D., \& Machin, G. (1997). A twin pronged attack on complex traits. Nature Genetics, 17, 387-392.

McCroskey, J.C., \& Young, T.J. (1979). The use and abuse of factor analysis in communication research. Human Communication Research, 5, 375-382.

Norton, R.W. (1978). Foundation of a communicator style construct. Human Communication Research, 4, 99-112.

Ozer, D.J. (1985). Correlation and coefficient of determination. Psychological Bulletin, 97, 307-315.

Rushton, J.P., Fulker, D.W., Neal, M.C., Nias, D.K.B., \& Eysenck, H.J. (1986). Altruism and aggression: The heritability of individual differences. Journal of Personality and Social Psychology, 50, 1192-1198.

Snyder, M. (1974). The self-monitoring of expressive behavior. Journal of Personality and Social Psychology, 30, 526-537.

Segal, N.L. (1999). Entwined lives: Twins and what they tell us about human behavior. New York: Dutton.

Shields, J. (1962). Monozygotic twins: Brought up apart and brought up together. London: Oxford University Press.

Spitz, E.R., Reed, T., Rusnel, M., Marchaland, C., Roubertoux, P., \& Carlier, M. (1996). Comparative diagnoses of twin zygosity by SSLP variant analysis, questionnaire, and dermatoglyphics analysis. Behavior Genetics, 26, 55-63.

Valencic, K.M., Beatty, M.J., Rudd,J.E., Dobos, J.A., \& Heisel, A.D. (1998). An empirical test of a communibiological model of verbal aggressiveness. Communication Quarterly, 46, 327-341.

Received: July 7, 2000

Final Revision Received: Jan 9, 2001

Accepted: January 12, 2001 
Copyright $\odot 2003$ EBSCO Publishing 